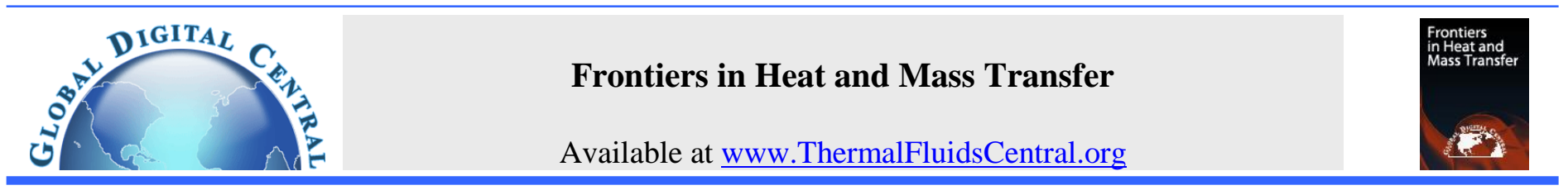

\title{
INVESTIGATION OF HEAT TRANSFER AND FLUID FLOW AROUND SINSOUDAL CORRUGATED CIRCULAR CYLINDER FOR TWO- DIMENSIONAL SYSTEM
}

\author{
Isam Mejbel Abed, Farooq H. Ali ${ }^{*}$, Shaymaa Abdul Munem Sahib \\ Mechanical Engineering Department, College of Engineering, University of Babylon, Hilla, Babylon, 51, Iraq
}

\begin{abstract}
Forced and mixed convection in 2-D, steady state, laminar flow and heat transfer around sinusoidal corrugated circular cylinder are numerically studied. Finite Element of Galerkin approach is used to analyze continuity, momentum and energy equation at Reynolds number $(\operatorname{Re}=10,45,100$, 200), Richardson Number $(\mathrm{Ri}=0,1,2)$, corrugation number $(\mathrm{G}=\infty, 3,4,5,10)$, amplitude values $(\lambda=0.1,0.2,0.3$ and 0.6$)$ for $\operatorname{Prandtl}$ number $(\operatorname{Pr}=$ 0.71). Results show the variation of corrugation number $\mathrm{G}$ and amplitude value $\lambda$ have important effect on the streamline , isothermal lines, local and average Nusselt number around the sinusoidal cylinder. The heat transfer is reduced as $46 \%$ compared to circular cylinder at $(\mathrm{G}=5$ and $\lambda=0.6)$. But $(\mathrm{G}=3,4$ for $\lambda=0.6)$ have more obstruction area against flow. An agreement validation is obtained between present and previous numerical results.
\end{abstract}

Keywords: Forced and mixed Convection; Sinusoidal corrugated circular cylinder; Galerkin Finite element; Reynolds and Richardson numbers.

\section{INTRODUCTION}

The regular or irregular circular cylinders are found in varied engineering employments, such as thermal management or cooling of electronic industry equipment, finned-tube of heat exchanger, the tube in the evaporator and condenser, heat exchanger of chemical reactor, flow around cooling tower and building, Bridge scour as explained by Amit and Mudassir (2012). Rupad and Spencer (2001) performed numerical solution of the flow past square cylinders with a sinusoidal along the span wise direction at both the leading and trailing edge surfaces by using a spectral element at $(\operatorname{Re}=10-150)$. It was observed that at low Reynold number, the boundary layers start to separate in the trailing edge. Lam and Lin (2009) studied a numerical solution of laminar flow past a sinusoidal circular cylinder wavering along their spanwise direction at $\operatorname{Re}=100$. Results showed that the wide wake occurs at the saddle plane of a minimum diameter, while a narrow wake takes place at the node plane at a maximum diameter. Subhankar et al. (2011) utilized Galerkin finite element approach to found the solution of flow past a square cylinder and showed it has the largest drag with bigger wake compared to a circular cylinder. Atul and Eswaran (2010) used finite volume method to study both steady flow $\operatorname{Re} \leq 40$ and unsteady flow $\operatorname{Re} \geq 50$ around square cylinder. Results showed the wake length increased with increasing Reynolds number in the steady flow. The Nusselt Number at the front surface is highest then at the rear and increased with increasing Reynolds number. James et al. (2020) carried out the flow and heat transfer around circular cylinder by using numerical simulations in the Reynolds numbers ranges (4- 188.5), and the implemented of the non-uniform form to control on boundary layer suction that eliminated separation flow. Results showed the controlled flows had a very small symmetrical wake, as there was no longer separated flow downstream. Amit et al. (2018) studied numerically the mixed convection of the heat transfer from the circular cylinder by

*Corresponding Author: Email: farooq_hassan77@yahoo.com using ANSYS at Reynolds number $(\mathrm{Re}=50,100,150)$ for Richardson number $(\mathrm{Ri}=0,1,2)$ at steady and unsteady regimes. Results observed that the average Nusselt number is increased to $94 \%$ with increasing the Reynold number to $(\operatorname{Re}=150)$, while the average Nusselt number is increased to $18 \%$ with increasing the Richardson number to $(\mathrm{Ri}=2)$. Dipankar and Bittagopal (2015) analysed numerically a flow and heat transfer across a semi-circular cylinder using ANSYS at $(\mathrm{Re}=50-150)$. Rresults observed a thick boundary layer is formed at the flat plane facing the flow, this configuration has the least heat transfer rate than the case of oriented curve face towards the flow.

Rajani et al. (2009) show that the wake length increased as the Reynolds number increased. Bharti and Eswaran (2007) found that the local Nusselt Number increased with an increased in Reynolds Number. Amnart and Withada (2018) examined numerically the flow effect and heat transfer influence in the heat exchanger as form of square channel that putted with ( $\mathrm{V}$ - baffle) in the laminar system at $(\mathrm{Re}=100-1000)$. The validation is done for the numerical model. Results show the gap ratio is effected on the enhancement of the heat transfer by comuting the Nusselt number. Hussein et al. (2019) studied numerically the natural convection in enclosure of sinusoidal form, which containing different shape of cylinders in the same area such as (square, circle, and equilateral triangle). The Governing equations are solved by using Galerkin Finite Element approach at prandtal number of air $(\mathrm{Pr}=0.71)$. The present paper is focued on the enhanceing or dissipation of heat transfer rate that attendant to the development of thermal management and effective cooling technology with low cost and without additional equipment. The design is complete by changing the shape of the outer surface circular cylinder to the sinusoidal corrugated circular cylinder when the flow and heat transfer be around it. Finally make comparison among them and with the circuler cylinder, as well as, this study produces an examination for the effect of variation the corrugation number at the ranges $(\mathrm{G}=\infty, 3,4,5,10)$ and amplitude value $(\lambda=0.1$, $0.2,0.3,0.6)$ on the stream line, isotherm line, local and average Nusselt number at $(\operatorname{Re}=10,45,100,200)$ and $(\mathrm{Ri}=0,1,2)$. 


\section{MATHEMATICAL MODELING}

The computational domain of the present study includes the sinusoidal cylinder that has a mean diameter $\left(D_{\text {mean }}\right)$ which has unit length, with node and saddle plans (see Fig. 1-A), and located symmetrically at the center of the domain at an upstream space $\mathrm{Xn}=10 \mathrm{D}$ after the inlet and at the downstream space of $\mathrm{Xm}=15 \mathrm{D}$ as of the outlet. It exposed to an inlet fully developed velocity profile has the maximum value $\mathrm{U}=\mathrm{Uo}$, the length of the domain is $L=\left(X_{n}+X_{m}\right)$ and the height of it is $H$, the space between the top and bottom part is $20 \mathrm{D}$ ( see Fig. 1- B). The flow stream at the inlet has cold temperature while the surface of cylinder kept at hot temperatures.

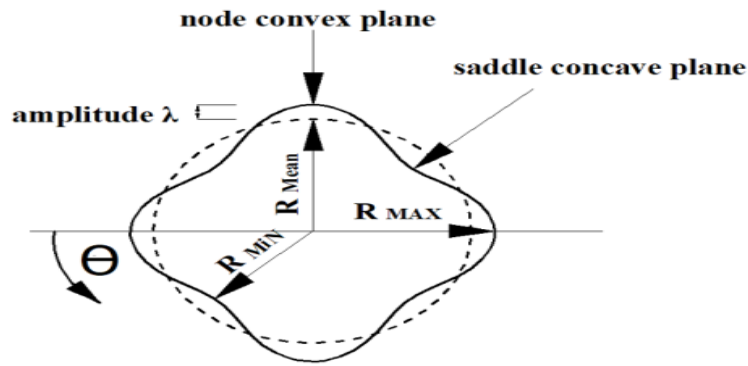

(a)

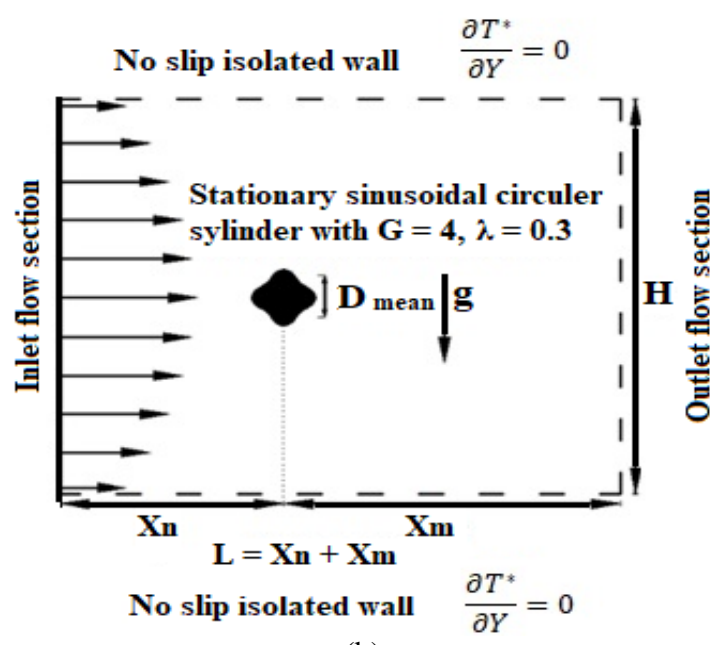

(b)

Fig. 1 Mathematical Modeling: (a) sinusoidal circular cylinder, $\lambda$ wave amplitude, $\mathrm{R}_{\text {Mean }}$ mean radius, $\mathrm{R}_{\mathrm{M} \text { iN }}$ smaller diameter and $\mathrm{R}_{\text {MAX }}$ larger diameter, (b) computational domain with boundary condition

A sinusoidal cylinder is located in domain Ammar et al (2019):

$$
\begin{aligned}
& x=\left[R_{\text {Mean }}+\frac{\lambda \sin \left(G \times \theta \times \frac{\pi}{180}\right)}{G}\right] \times\left(\cos \left(\theta \times \frac{\pi}{180}\right)\right) \\
& X=\left\{\frac{\left[R_{\text {Mean }}+\frac{\lambda \sin \left(G \times \theta \times \frac{\pi}{180}\right)}{G}\right] \times\left(\cos \left(\theta \times \frac{\pi}{180}\right)\right)}{D}\right\} \\
& y=\left[R_{\text {Mean }}+\frac{\lambda \sin \left(G \times \theta \times \frac{\pi}{180}\right)}{G}\right] \times\left(\sin \left(\theta \times \frac{\pi}{180}\right)\right) \\
& Y=\left\{\frac{\left[R_{\text {Mean }}+\frac{\lambda \sin \left(G \times \theta \times \frac{\pi}{180}\right)}{G}\right] \times\left(\sin \left(\theta \times \frac{\pi}{180}\right)\right)}{D}\right\}
\end{aligned}
$$

\subsection{Governing equation and numerical solution}

The continuity, Momentum and energy equations of the steady state 2D flow are converted from dimensional to dimensionless form, as introduced by Isam et al (2020), as follows:

$$
\begin{gathered}
X=\frac{x}{D} ; Y=\frac{y}{D} ; U=\frac{u}{u_{o}} ; V=\frac{v}{u_{o}} ; P=\frac{p}{\rho u^{2}} ; T^{*}=\frac{T-T_{c}}{T_{h}-T_{c}} ; \\
R i=\frac{G r}{R e^{2}} ; \operatorname{Pr}=\frac{v}{\propto} ; \propto=\frac{k}{\rho C_{P}} ; v=\frac{\mu}{\rho} ; \operatorname{Pr}=\frac{\rho C_{p}}{k} ; R e \\
=\frac{\rho u D}{\mu} ; G r=\frac{g ß\left(T_{c}-T_{h}\right) D 3}{v^{2}}
\end{gathered}
$$

Where $\mathrm{x}$ and $\mathrm{y}$ are the dimensional axis in the cartesian coordinates, $\mathrm{u}$ and $\mathrm{v}$ are the dimensional velocity components, $\mathrm{T}_{\mathrm{h}}$ is hot temperature, $\mathrm{T}_{\mathrm{c}}$ is temperature cold, $\propto$ is the diffusivity, $v$ is the kinematic viscosity and $B$ is the volumetric expansion, $g$ is the gravitational acceleration, $\rho$ is the density, $\mathrm{C}_{\mathrm{p}}$ is the specific heat, $\mathrm{k}$ is the conductivity, $\mathrm{X}$ and $\mathrm{Y}$ are the non - dimensional axis, $\mathrm{U}$ and $\mathrm{V}$ are non- dimensional velocity components, $\mathrm{T}^{*}$ is non- dimensional temperature, and $\mathrm{Gr}$ is the Grashof number. The dimensionless form of the governing equations is written as referred by Gautam and Sandip (2009):-

$$
\begin{array}{lr}
\frac{\partial U}{\partial X}+\frac{\partial V}{\partial Y}=0 & \text { Continuity equation } \\
U \frac{\partial U}{\partial X}+V \frac{\partial U}{\partial Y}=-\frac{\partial P}{\partial X}+\frac{1}{R e}\left(\frac{\partial^{2} U}{\partial X^{2}}+\frac{\partial^{2} U}{\partial Y^{2}}\right) & \mathrm{X}-\text { momentum } \\
U \frac{\partial V}{\partial X}+V \frac{\partial V}{\partial Y}=-\frac{\partial P}{\partial Y}+\frac{1}{R e}\left(\frac{\partial^{2} V}{\partial X^{2}}+\frac{\partial^{2} V}{\partial Y^{2}}\right)+R i\left(T^{*}\right) & \mathrm{Y}-\text { momentum } \\
U \frac{\partial T^{*}}{\partial X}+V \frac{\partial T^{*}}{\partial Y}=\frac{1}{\operatorname{Pr} R e}\left(\frac{\partial^{2} T^{*}}{\partial X^{2}}+\frac{\partial^{2} T^{*}}{\partial Y^{2}}\right) & \text { Energy equation }
\end{array}
$$

The flow field around the sinusoidal cylinder can be signified by the stream function $(\psi)$ gotten from the components of the velocity $U$ and $V$ as expressed by Batchelor (1993):

$\frac{\partial^{2} \psi}{\partial X^{2}}+\frac{\partial^{2} \psi}{\partial Y^{2}}=\frac{\partial U}{\partial Y}-\frac{\partial V}{\partial X}$

Local and average Nusselt number can be written as a form that referred by Gautam and Sandip (2009):

$N u_{l o c}=\left.\frac{\partial T^{*}}{\partial n}\right|_{\text {along the courregate cylinder surfase }}$

Where $\mathrm{n}$ is the normal direction of the surface of the sinusoidal corrugated circular cylinder. The average Nusselt number $\overline{\mathrm{Nu}}$ over a length of hot surface can be transcribed as follows:-

$\overline{N u}=\frac{1}{\mathcal{L}} \int_{0}^{\mathcal{L}} \frac{\partial T^{*}}{\partial n} N u_{l o c} d \theta$

Where $\mathcal{L}$ is the circumference of the sinusoidal circular cylinder.

\subsection{Boundary conditions}

The assumption of the boundary conditions to apply for the domain are given in Table. 1.

Table 1 Boundary Condtions

\begin{tabular}{|l|l|l|l|}
\hline position & $U$ & $V$ & $T^{*}$ \\
\hline $\begin{array}{l}\text { No slip, } \\
\text { isolated } \\
\text { horizontal walls } \\
\text { of the domain }\end{array}$ & $\mathrm{U}=0$ & $\mathrm{~V}=0$ & $\frac{\partial \mathrm{T}^{*}}{\partial \mathrm{Y}}=0$ \\
\hline $\begin{array}{l}\text { Inlet of the } \\
\text { domain }\end{array}$ & $\begin{array}{l}\text { A fully developed velocity } \\
\text { profile Amit Dhiman } \text { et al. } \\
(2018) \\
U=1.5\left[1-(1-2 Y)^{2}\right]\end{array}$ & $\mathrm{V}=0$ & $\mathrm{~T}^{*}=0$ \\
\hline $\begin{array}{l}\text { Outlet of the } \\
\text { domain }\end{array}$ & $\mathrm{P}=0$ & ----- & ----- \\
\hline $\begin{array}{l}\text { sinusoidal } \\
\text { cylinder } \\
\text { Surface }\end{array}$ & $\mathrm{U}=0$ & $\mathrm{~V}=0$ & $\mathrm{~T}^{*}=1$ \\
\hline
\end{tabular}

\subsection{Weak formulation}

The continuity, momentum and energy equation for Eqs. (6) to (9) are solved by using the Galerkin approach of finite element method. The 
penalty parameter $\mathrm{V}$ is used to eliminate the pressure showed by Tanmay et al (2006). The Eq. (6) give the incompressibility criteria which results in:

$P=-\gamma\left(\frac{\partial U}{\partial X}+\frac{\partial V}{\partial Y}\right)$

The momentum equations in $\mathrm{X}$ and $\mathrm{Y}$ direction of Eqs. (7) and (8), respectively, as showed by Tanmay et al (2006) can reduce to:-

$U \frac{\partial U}{\partial X}+V \frac{\partial U}{\partial Y}=$

$\mathrm{Y} \frac{\partial}{\partial X}\left(\frac{\partial U}{\partial X}+\frac{\partial V}{\partial Y}\right)+\frac{1}{R e}\left(\frac{\partial^{2} U}{\partial X^{2}}+\frac{\partial^{2} U}{\partial Y^{2}}\right)$

in $\mathrm{X}$ direction

$U \frac{\partial V}{\partial X}+V \frac{\partial V}{\partial Y}=$

$\mathrm{\gamma} \frac{\partial}{\partial Y}\left(\frac{\partial U}{\partial X}+\frac{\partial V}{\partial Y}\right)+\frac{1}{R e}\left(\frac{\partial^{2} V}{\partial X^{2}}+\frac{\partial^{2} V}{\partial Y^{2}}\right)+R i\left(T^{*}\right)$ in Y direction

The residual equation for Eqs. (7) to (9) as showed by Rehena (2011), can be given as below:

$R_{i}^{(1)}=$

$\sum_{b=1}^{S} U_{b} \int_{\Omega}\left[\left(\sum_{b=1}^{S} U_{b} \phi_{b}\right) \frac{\partial \phi_{b}}{\partial X}+\left(\sum_{b=1}^{S} V_{b} \phi_{b}\right) \frac{\partial \phi_{b}}{\partial Y}\right] \phi_{i} d X d Y+$

$\mathrm{\gamma}\left[\sum_{b=1}^{S} U_{b} \int_{\Omega} \frac{\partial \phi_{i}}{\partial X} \frac{\partial \phi_{b}}{\partial X} d X d Y+\sum_{b=1}^{S} V_{b} \int_{\Omega} \frac{\partial \phi_{i}}{\partial X} \frac{\partial \phi_{b}}{\partial Y} d X d Y\right]+$

$\frac{1}{R e} \sum_{b=1}^{S} U_{b} \int_{\Omega}\left[\frac{\partial \phi_{i}}{\partial X} \frac{\partial \phi_{b}}{\partial X}+\frac{\partial \phi_{i}}{\partial Y} \frac{\partial \phi_{b}}{\partial Y}\right] d X d Y$

$R_{i}^{(2)}=\sum_{b=1}^{S} V_{b} \int_{\Omega}\left[\left(\sum_{b=1}^{S} U_{b} \phi_{b}\right) \frac{\partial \phi_{b}}{\partial X}+\left(\sum_{b=1}^{S} V_{b} \phi_{b}\right) \frac{\partial \phi_{b}}{\partial Y}\right] \phi_{i} d X d Y+$ $\gamma\left[\sum_{b=1}^{S} U_{b} \int_{\Omega} \frac{\partial \phi_{i}}{\partial Y} \frac{\partial \phi_{b}}{\partial X} d X d Y+\sum_{b=1}^{S} V_{b} \int_{\Omega} \frac{\partial \phi_{i}}{\partial Y} \frac{\partial \phi_{b}}{\partial Y} d X d Y\right]+$

$\frac{1}{R e} \sum_{b=1}^{S} V_{b} \int_{\Omega}\left[\frac{\partial \phi_{i}}{\partial X} \frac{\partial \phi_{b}}{\partial X}+\frac{\partial \phi_{i}}{\partial Y} \frac{\partial \phi_{b}}{\partial Y}\right] d X d Y+$

$\frac{1}{R e} \int_{\Omega}\left(\sum_{b=1}^{S} V_{b} \phi_{b}\right) \phi_{i} d X d Y+$

$\operatorname{Re} \int_{\Omega}\left(\sum_{b=1}^{S} T^{*}{ }_{b} \phi_{b}\right) \phi_{i} d X d Y$

$R_{i}^{(3)}=$

$\sum_{b=1}^{S} T^{*}{ }_{b} \int_{\Omega}\left[\left(\sum_{b=1}^{S} U_{b} \phi_{b}\right) \frac{\partial \phi_{b}}{\partial X}+\left(\sum_{b=1}^{s} V_{b} \phi_{b}\right) \frac{\partial \phi_{b}}{\partial Y}\right] \phi_{i} d X d Y+$

$\sum_{b=1}^{S} T^{*}{ }_{b}\left[\int_{\Omega} \frac{\partial \phi_{i}}{\partial X} \frac{\partial \phi_{b}}{\partial X} d X d Y+\right.$

$\left.\int_{\Omega} \frac{\partial \phi_{i}}{\partial Y} \frac{\partial \phi_{b}}{\partial Y} d X d Y\right]$

Where (S) is the total nodes number and (b) denoted to the node number. the linear residual equations of stream equation for Eq. (10) that is yielded to the Galerkin approach of the finite element method and showed by Batchelor (1993) as below:

$R_{i}^{s t}=$

$\sum_{b=1}^{S} \psi_{b} \int_{\Omega}\left[\frac{\partial \phi_{i}}{\partial X} \frac{\partial \phi_{b}}{\partial X}+\frac{\partial \phi_{i}}{\partial Y} \frac{\partial \phi_{b}}{\partial Y}\right] d X d Y+\sum_{b=1}^{S} U_{b} \int_{\Omega} \phi_{i} \frac{\partial \phi_{b}}{\partial Y} d X d Y-$ $\sum_{b=1}^{s} V_{b} \int_{\Omega} \phi_{i} \frac{\partial \phi_{b}}{\partial X} d X d Y$

The discretization of the local and average Nusselt number can be applied to the Eqs. (11) and (12) as showed by Tanmay et al (2006) as below:

$$
\begin{aligned}
& N u= \\
& \frac{1}{\mathcal{L}} \sum_{b=1}^{s} T^{*}{ }_{b} \sqrt{\left(\frac{\partial \phi_{b}}{\partial X}\right)^{2}+\left(\frac{\partial \phi_{b}}{\partial Y}\right)^{2}}
\end{aligned}
$$

$\overline{N u}=$

$\frac{1}{\mathcal{L}} \sum_{b=1}^{S} T^{*}{ }_{b} \int_{0}^{\mathcal{L}} \sqrt{\left(\frac{\partial \phi_{b}}{\partial X}\right)^{2}+\left(\frac{\partial \phi_{b}}{\partial Y}\right)^{2}} d \exists$

Where $\exists$ Indicates the angle with new coordinates. The numerical grid generation is represented (See Fig. 2 and Table. 2).

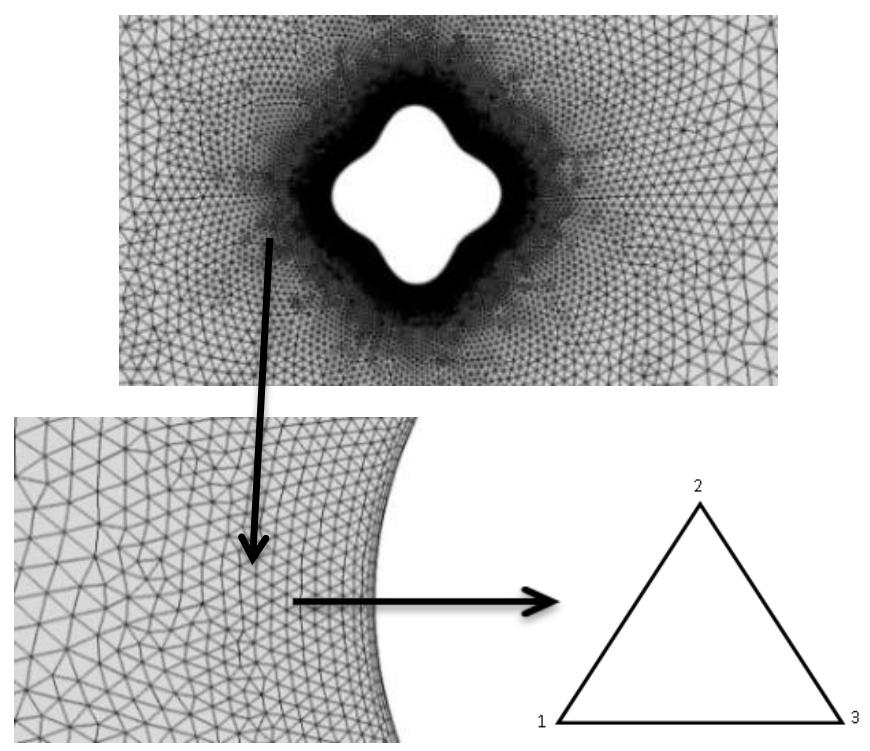

Fig. 2 computational domain within the triangle mesh type of extremely fine corrugated cylinder, $G=4$ with amplitude $\lambda=0$

Table 2 Relation between the element number and the average Nusselt Number for sinusoidal corrugated cylinder for $G=4, \lambda=0.3$ at $\mathrm{Re}=10,200$ and $\mathrm{Ri}=1$

\begin{tabular}{|l|l|l|l|l|l|l|}
\hline Mesh type & $\begin{array}{l}\text { Element } \\
\text { number }\end{array}$ & $\begin{array}{l}\text { boundary } \\
\text { element }\end{array}$ & $\begin{array}{l}\overline{\mathbf{N u}} \text { at } \\
R e=10\end{array}$ & error & $\begin{array}{l}\overline{\mathbf{N u}} \text { at } \\
R e=200\end{array}$ & error \\
\hline $\begin{array}{l}\text { Extremely } \\
\text { fine }\end{array}$ & 60022 & 1152 & 1.75 & 1.75 & 6.56 & 6.56 \\
\hline finer & 27738 & 876 & 1.75 & 0 & 6.67 & 0.11 \\
\hline fine & 18828 & 746 & 1.75 & 0 & 6.71 & 0.04 \\
\hline normal & 12733 & 717 & 1.75 & 0 & 6.75 & 0.04 \\
\hline
\end{tabular}

\subsection{Validation of the numerical results}

The present numerical results for circular cylinder are validated with Gautam and Sandip (2009) in the streamlines, isotherm contours, local Nusselt Number and angles of separation $\theta_{\mathrm{s}}$ with a good agreement is obtained from these validation (see Figs. 3 to 5 and Table. 3 ).

(h)
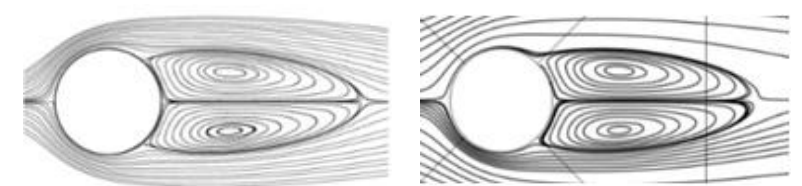

(f)
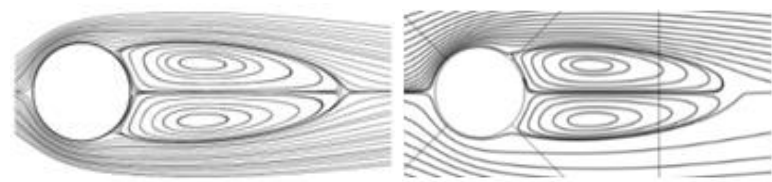

$(\mathrm{g})$

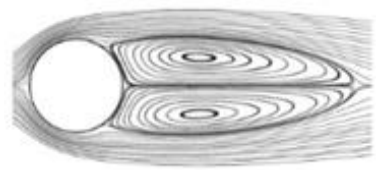

(a)

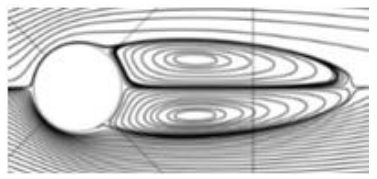

(b)
Fig. 3 A comparison between simulation of the streamline by (a) Gautam and Sandip (2009) and (b) present study for a circular cylinder at $\mathrm{h}) \operatorname{Re}=35, \mathrm{f}) \mathrm{Re}=40$ and g) $\operatorname{Re}=45$ 
(h)
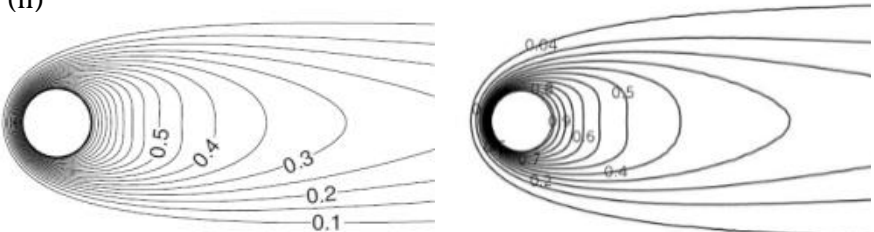

(f)
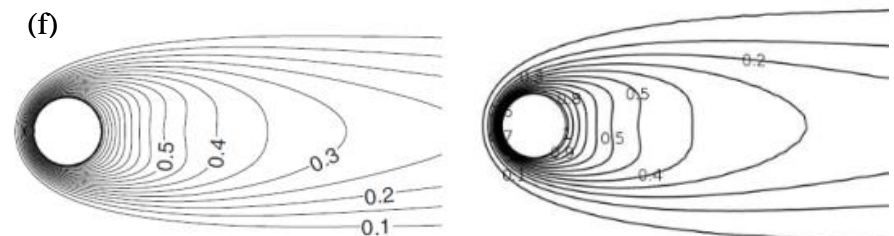

(g)

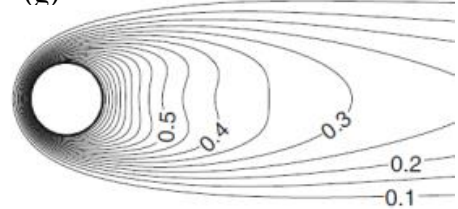

(a)

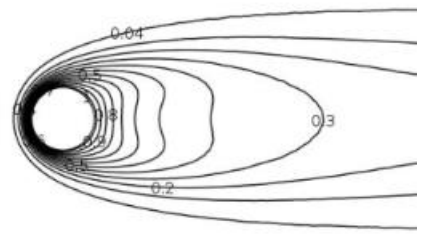

(b)

Fig. 4 A comparison between simulation of the isotherm contour by (a) Gautam and Sandip (2009) and (b) the present study for a circular cylinder at $h) \operatorname{Re}=35, \mathrm{f}) \mathrm{Re}=40$ and $\mathrm{g}$ ) $\mathrm{Re}=45$.
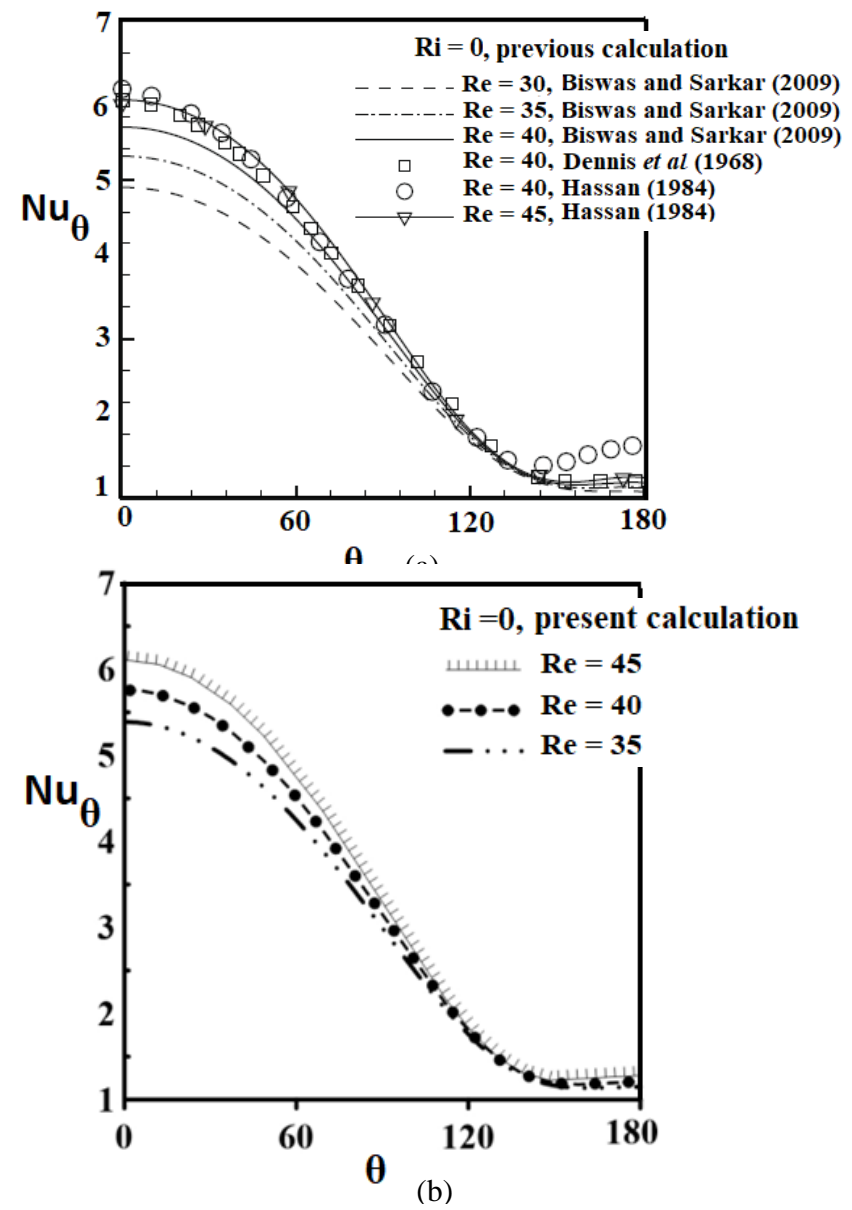

Fig. 5 A comparison between simulation of the Local Nusselt Number by (a) Gautam and Sandip (2009) and (b) the present study for circular cylinder at $\operatorname{Re}=35,40,45$.

Table 3 A comparison of angle of separation $\theta \mathrm{s}$ at Re Number ranges between Gautam and Sandip (2009) and the present study at Re $=(35,40$ and 4$)$ for $\mathrm{Ri}=0$.

\begin{tabular}{|c|c|c|c|}
\hline$R e$ & $\begin{array}{c}\theta_{s} \text { of Present } \\
\text { calculation }\end{array}$ & $\begin{array}{c}\theta_{s} \text { of Gautam and } \\
\text { Sandip (2009) }\end{array}$ & Error \\
\hline 35 & 52.11 & 51.35 & $0.014 \%$ \\
40 & 53.74 & 53.10 & $0.012 \%$ \\
45 & 54.98 & 54.56 & $0.0076 \%$ \\
\hline
\end{tabular}

\section{NUMERICAL RESULTS AND DISCUSSION}

The numerical results of heat transfer effect and flow pattern under forced and mixed convection at $\mathrm{Re}=(10,45,100,200)$ and $\mathrm{Ri}=(0,1$, 2) of corrugation number $\mathrm{G}=(\infty, 3,4,5,10)$ with amplitude values $\lambda=$ $(0.1,0.2,0.3,0.6)$, where $\mathrm{G}=\infty$ represents to the circular cylinder.

\subsection{Influence of Corrugation Number and Amplitude on the Streamline Contours.}

The streamlines contours are observed in the Figs. (6) and (7), where rows represented the effect of amplitude while columns represented the effect of the corrugation number for $\mathrm{Ri}=0$ at $\mathrm{Re}=10$ and 200 , respectively, also a comparison between the sinusoidal corrugated circular cylinders with the circular cylinder was achieved in these streamline contours. As can seen a symmetrical behavior about the horizontal centerline of wake cells behind the sinusoidal cylinders due to the non-appearance of the thermal buoyancy in the pure forced convection with the Richardson number is equal to zero. The cells wide behind the Corrugated cylinder increase with decreasing number of corrugation, and this lead to increase the obstruction area due to increase the separation wake size at the rear, which cause early separation due to increase the distance between the upper and lower node convex plane for the corrugation number $\mathrm{G}=4$ as compared with circular cylinder. The shape of sinusoidal cylinder with $\mathrm{G}=3$ make a big vacuum at the rear that increase the obstructed area. The increase in amplitude value $\lambda$ lead to increase the depth of the concave saddle surface that allow to extend the wake inward the cave behind the sinusoidal corrugated circular cylinder. Figs. 6 (c, d) shows the sinusoidal circular cylinder with $(\mathrm{G}=4$ and 3$)$ at amplitude $(\lambda=0.3,0.6)$ have the highest obstruction as compared with circular and another sinusoidal cylinder due to the enlarged in the length and width of the wake cell at the rear. Figure. 7 show the streamlines for different corrugation number and amplitude $(\lambda=0.1,0,6)$ at $\mathrm{Re}=200$. At the case of sinusoidal corrugated circular cylinder with $\mathrm{G}=4$ and amplitude $\lambda$ $=0.6$ at $\operatorname{Re}=200$, they have the highest obstruction area because of the symmetrical cells behind the sinusoidal cylinders becomes more elongation since the Reynolds number increase. In the case of mixed convection, the normal buoyancy force on the flow lead to push the wake cells toward the upper edge and formed the non - symmetrical cells contain the primary small wake at lower and secondary larger wake at upper. Figure. 8 explains the sinusoidal circular cylinder of corrugation number $\mathrm{G}=4$ and $\lambda=0.6$ has the highest obstruction area after that the $\mathrm{G}=3, \mathrm{G}=5, \mathrm{G}=10$, then $\mathrm{G}=\infty$, also the increasing depth of the concave saddle surface by the increasing amplitude meet with the effect of the thermal buoyancy, which help to push the wake inside the cave lead to extend the non - symmetric two cells inside any cave at the rear and increase the reverse flow then also cause increasing in the obstruction area at the rear. Figure. 9 shows the combined effect of increasing the Reynold number with more effect of buoyancy at $\mathrm{Ri}=2$ for $\operatorname{Re}=200$. As the Reynolds Number increased, the length of the narrow wake cells is increased and the two lower small wake pushed toward the upper edge, also the upper large wake and lower small wake are formed at the rear. 


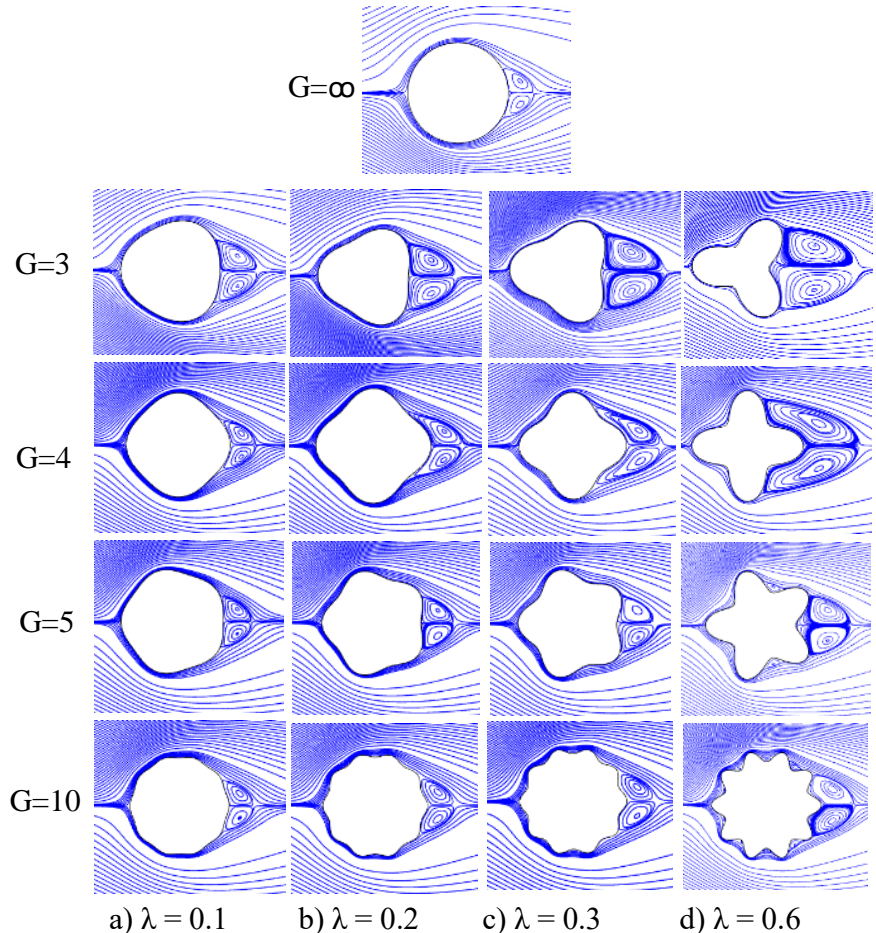

Fig. 6 Streamline for the sinusoidal cylinders of $\mathrm{G}=\infty, 3,4,5,10$ at $\operatorname{Re}$ $=10, \mathrm{Ri}=0$ with a) $\lambda=0.1$, b) $\lambda=0.3$, c) $\lambda=0.3$, d) $\lambda=0.6$.

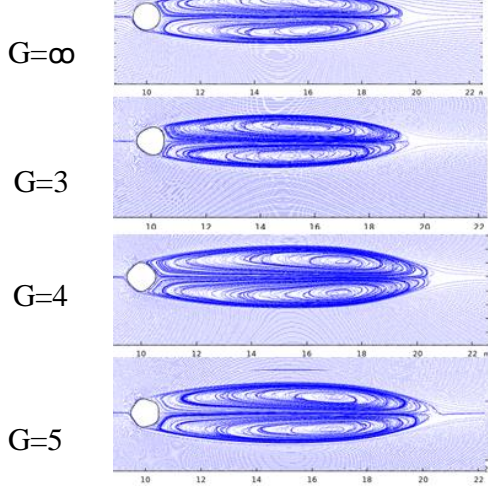

a) $\lambda=0.1$

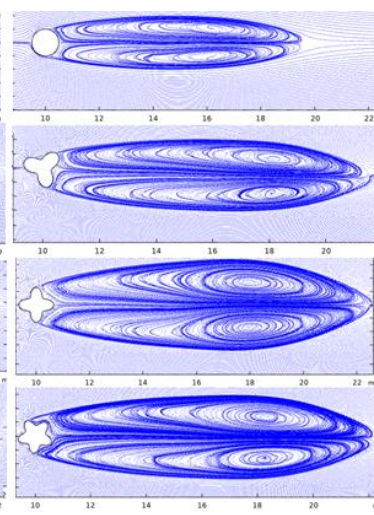

b) $\lambda=0.6$
Fig. 7 Streamline for the sinusoidal cylinders of $\mathrm{G}=\infty, 3,4$ and 5 at $\mathrm{Re}=200, \mathrm{Ri}=0$ with a) $\lambda=0.1, \mathrm{~b}) \lambda=0.6$.

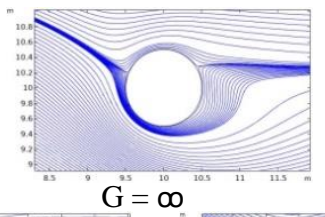

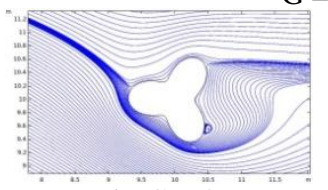

b) $\mathrm{G}=3$

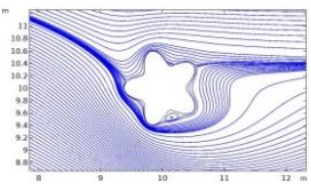

d) $\mathrm{G}^{10}=5$

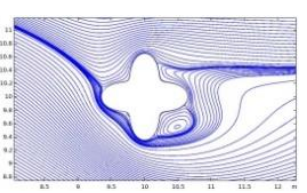

c) $\mathrm{G}=4$

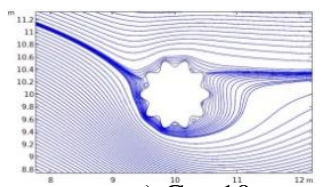

e) $\mathrm{G}^{10}=10$
Fig. 8 Streamline for the sinusoidal cylinders with $\lambda=0.6$ at $\operatorname{Re}=10$, $\mathrm{Ri}=1$ for a) $\mathrm{G}=\infty$, b) $\mathrm{G}=3$,c) $\mathrm{G}=4$, d) $\mathrm{G}=5$, e) $\mathrm{G}=10$.

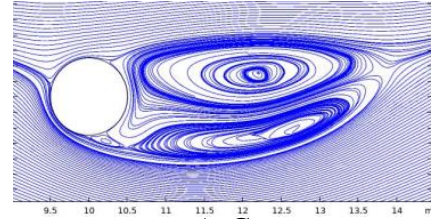

a) $\stackrel{121}{G}=\infty$

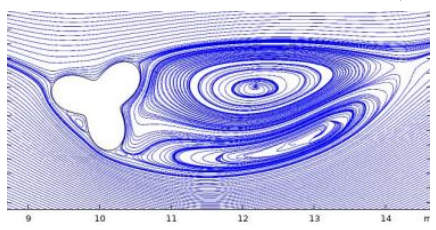

b) $\mathrm{G}=3$

d) $\mathrm{G}=5$

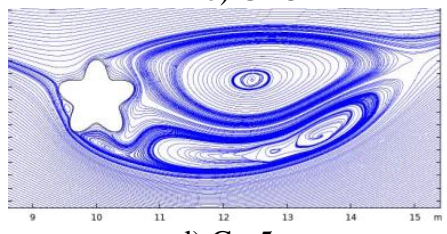

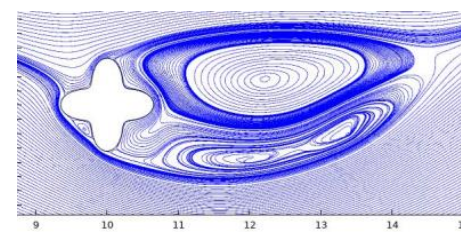

c) $\mathrm{G}=4$

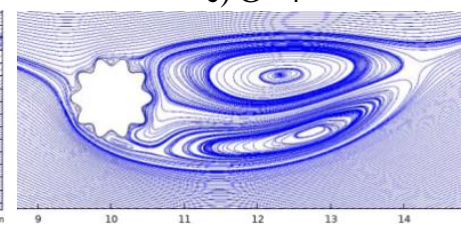

e) $\mathrm{G}=10$
Fig. 9 Streamline for the sinusoidal cylinders with $\lambda=0.6$ at $\operatorname{Re}=200$, $\mathrm{Ri}=2$ for a) $\mathrm{G}=\infty$, b) $\mathrm{G}=3$, c) $\mathrm{G}=4$, d) $\mathrm{G}=5$, e) $\mathrm{G}=10$.

\subsection{Temperature distribution (isotherm line)}

Figure. 10 shows the symmetrical isotherms at $\mathrm{Ri}=0$ and $\mathrm{Re}=10$ due to the symmetrical boundary layer, which be thicker at the rear for the sinusoidal cylinder of $\mathrm{G}=4$ at $\lambda=0.6$ that has the longest isotherm line than circular cylinder in the centerline of the wake cell zone at the rear allows to a higher temperature gradient, which allows to increase the heat transfer. Figure. 11 shows the isotherm contours of the sinusoidal cylinder appears the same as the behavior around the circular cylinder with a little extend. The isotherm contour closer to the bottom of the rear cylinder, then the sequence of transportation of the thermal energy starts with stretching a hot strand of warm fluid, originating in the nearest of the sinusoidal cylinder into the cylinder near wake, a local extreme temperature is found at the tip of the strand. Figure. 12 shows the isotherm of $\mathrm{G}=3$ and 4 at $\lambda=0.6$ be have a strong recirculation zone in line of 0.04 and 0.3 because combined of more effect of bouncy force with a large obstruction area of low corrugation number .

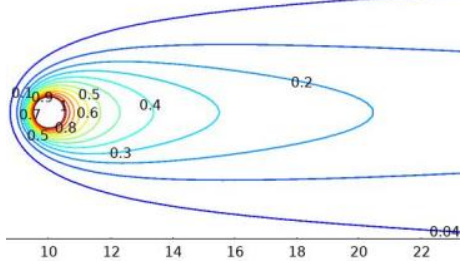

a) $\mathrm{G}=\infty$
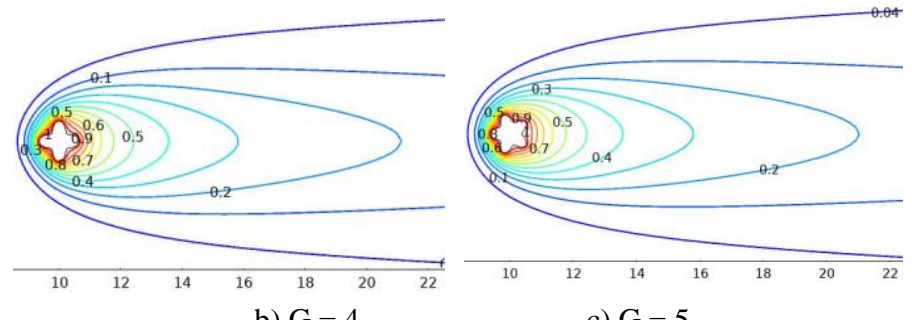

b) $\mathrm{G}=4$

c) $\mathrm{G}=5$

Fig. 10 Isotherm line for sinusoidal cylinders of $\mathrm{G}=\infty, 4$ and 5 with $\lambda=0.6$ at $\mathrm{Re}=10, \mathrm{Ri}=0$. 


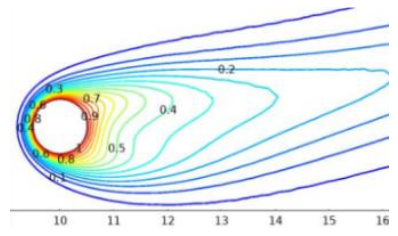

a) $\mathrm{G}=\infty$

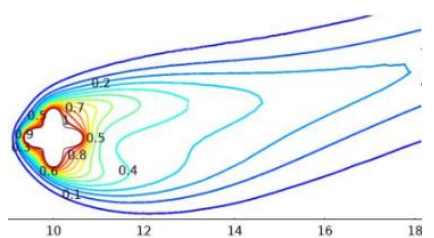

b) $\mathrm{G}=4$

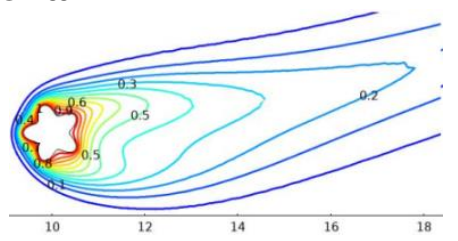

c) $\mathrm{G}=5$
Fig. 11 isotherm line for the sinusoidal cylinders of $\lambda=0.6$ At $\operatorname{Re}=$ 45, $\mathrm{Ri}=1$ with a) $\mathrm{G}=\infty$, b) $\mathrm{G}=4$, c) $\mathrm{G}=5$.

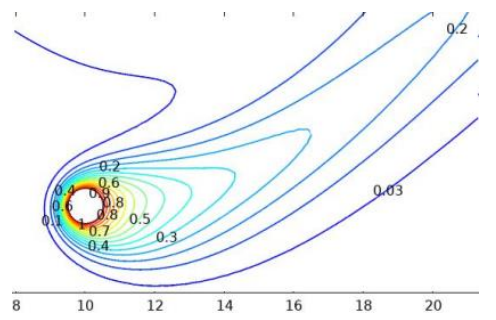

a) $\mathrm{G}=\infty$

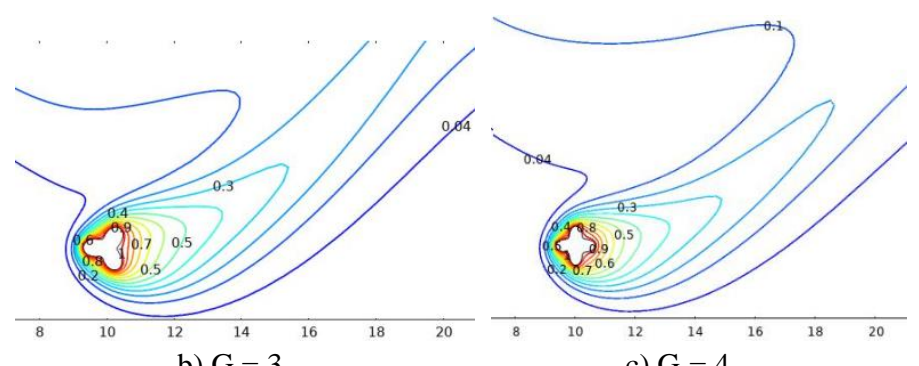

b) $\mathrm{G}=3$

c) $\mathrm{G}=4$

Fig. 12 Isotherm line for sinusoidal cylinders of $\mathrm{G}=\infty, 3$, 4 with $\lambda=0.6$ at $\mathrm{Re}=10$ for $\mathrm{Ri}=2$.

\subsection{Influence The Corrugation Number and Amplitude on Local Nusselt Number}

Figure. 13 shows that the local Nusselt number for different corrugation number $(\mathrm{G}=\infty, 3,4,5,10)$ and amplitude $(\lambda=0.1,0.6), \mathrm{Ri}=0, \mathrm{Re}=$ 10. It is showed a sinusoidal behavior alternates quickly between higher local Nusselt Number at the thinner boundary layer of the convex node plane and the lower local Nusselt Number at concave saddle plane, which include small separation region lead to thicker boundary layer on its surface. The local Nusselt number at the forward of the sinusoidal corrugated circular cylinder is highest value due to smaller thermal resistance of thinner boundary layer and decreases gradually to the lowest value at the rearward. The number of waves equal to the number of corrugation (see Fig. 13(a)), which explain the corrugated cylinder with the value of $(\mathrm{G}=3$ and $\lambda=0.1)$ has the higher value of the rate of heat transfer than circular and another corrugated cylinder due to the thinner boundary layer in the wide surface orientation to the incoming air, as a result of increase the distance between two series edge, as well as, decrease in the depth between them. The increase in the amplitude value $\lambda$ combined with more wavy number cause an increasing of the number of undulations in the sinusoidal wavy behavior with very fast rise and fall of local Nusselt number value due to decrease the distance between the two consecutive convex edges and cause an increase in depth of the concave surface (see Fig. 13(b)) for the corrugated cylinder with $(\mathrm{G}=10$ and $\lambda=0.6)$. The local Nusselt number reaches to a higher value for higher Reynolds number due to the wall boundary layer is accelerated and became thinner in the upstream orientation surface on the sinusoidal corrugated circular cylinder surface, also the separation flow is delayed and lead to close the narrow wake cells with confuse the wake cells inside the cave behind the sinusoidal cylinder, which increase the heat transfer rate.

In the case of mixed convection, the heat transfer rate increases significantly because of the buoyancy force push the wake cells toward the close of the upper edge, which lead to form primary small lower wake and secondary large upper wake at rearward of the sinusoidal circular cylinder. The strong effect of buoyancy force due to increase Richardson and Reynolds number lead to delay separation flow at the upper and lower side of the corrugated cylinder that cause the narrow wake cell and close it to the rear surface of the corrugated cylinder, which lead to enhance the heat transfer at the rear in addition to the enhancement at forward sinusoidal corrugated cylinder due to the increase Reynold Number, which accelerate boundary layer with make it thinner. The behavior of the sinusoidal local Nusselt number is influenced by both corrugation number and buoyancy force together. Figure. 14 shows the sinusoidal local Nusselt number has higher value in the sinusoidal cylinder has less wavy number due to increase the distance between two series edge lead to reduce the depth between them, which allows to the wide surface exposed to the incoming flow and increases the heat transfer at the forward, in addition to the buoyancy force push the wake cells inward the concave and make it very close and focus on it at the rear, also the shape of sinusoidal cylinder with $\mathrm{G}=3$ has concave edges are inclined to the rear that help to delay separation flow, which contributes to increased heat transfer due to increase the distance that the fluid flows on it.

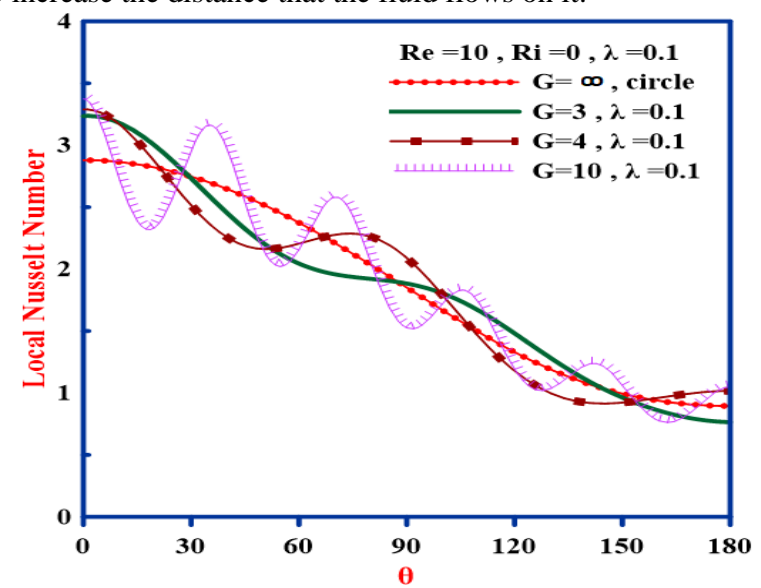

a) $\lambda=0.1$

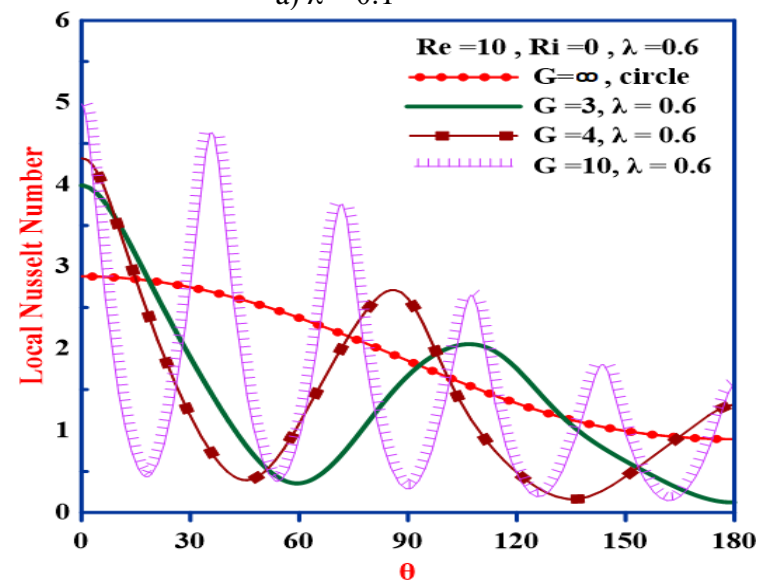

b) $\lambda=0.6$

Fig. 13 Local Nusselt number for sinusoidal cylinders of $G=\infty, 3,4$ and 10 at $\operatorname{Re}=10, \mathrm{Ri}=0$ with a) $\lambda=0.1, \mathrm{~b}) \lambda=0.6$ 


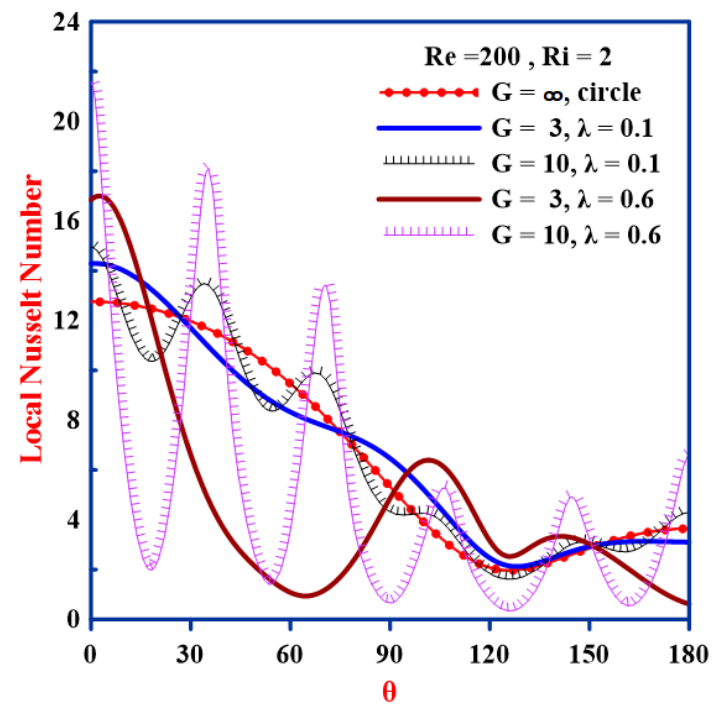

Fig. 14 Local Nusselt number for sinusoidal cylinders of $G=\infty, 3$ and 10 with $\lambda=0.6$ at $\operatorname{Re}=200$ for $\mathrm{Ri}=2$.

\subsection{Influence The Corrugation Number and Amplitude on Average Nusselt Number}

The average Nusselt number is the integration of the curve that contains all higher waves with the all lower waves of the sinusoidal local Nusselt number. In this integration, the increase in heat at the convex waves eliminate the decrease in heat at the concave waves. Fig. 15 shows the average Nusselt number has the least value of the higher corrugation number $\mathrm{G}=10$ and amplitude value $\lambda=0.6$ at $\mathrm{Re}=10$ and $\mathrm{Ri}=0$. The average Nusselt number increase as the Richardson number increase. Figures. 16 and 17 show that the increasing in the buoyancy force and the Reynold numbers at $(\operatorname{Re}=200$ and $\mathrm{Ri}=2)$ lead to increase the average Nusselt number for the sinusoidal cylinder with $\mathrm{G}=3$ and $\lambda=$ 0.1 compared to the circular cylinder and another sinusoidal corrugated cylinders, due to increase the distance between the two series convex edges that cause increase the surface exposing to the incoming flow, also the less corrugation number contribute for decreasing the separation zones that have less local Nusselt number due to thicker boundary layer in those regions, also the low amplitude value lead to decrease cave of the separation regions of the concave saddle surfaces.

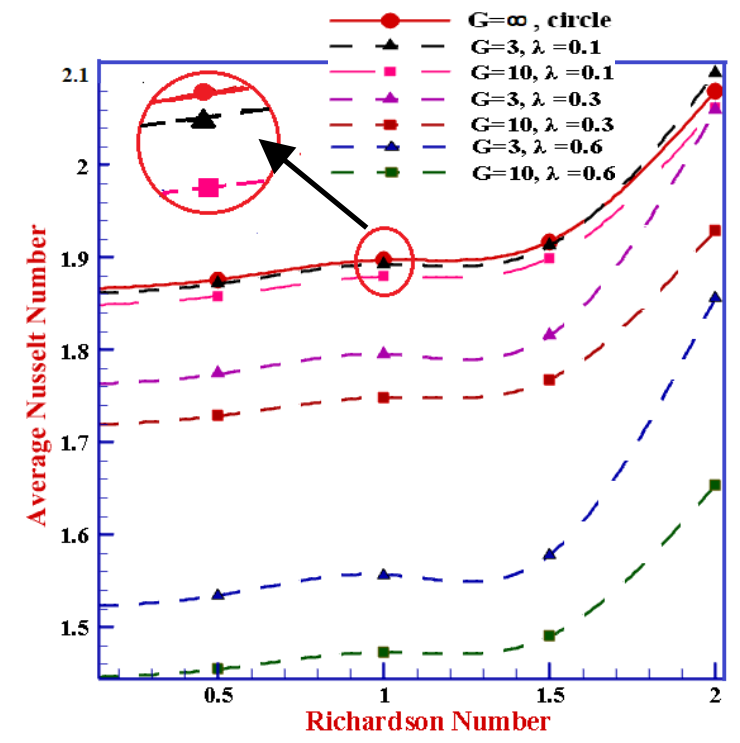

Fig. 16 Average Nusselt Number for sinusoidal cylinders of $\mathrm{G}=\infty, 3$, 10 at $\operatorname{Re}=10$ and $\mathrm{Ri}=0,0.5,1,1.5,2$ with $\lambda=0.1,0.3,0.6$.

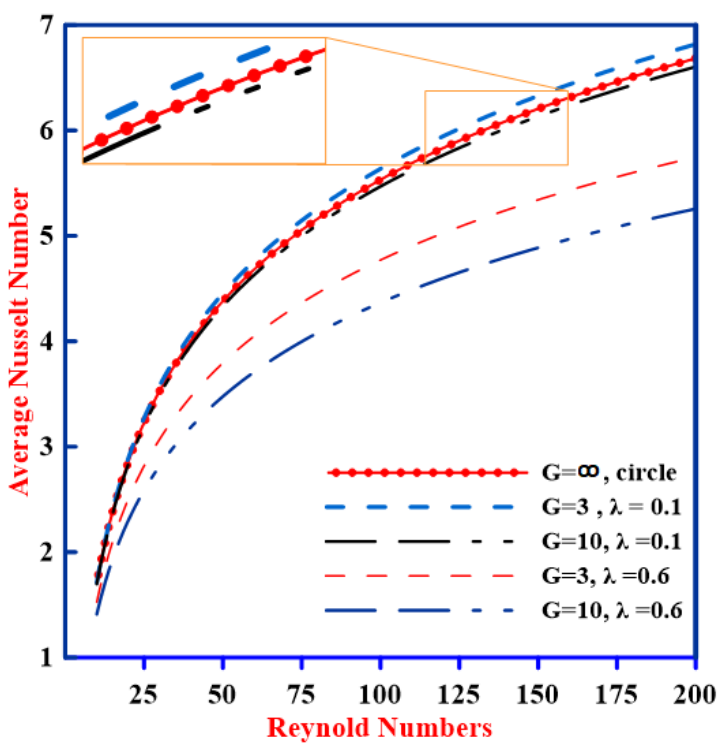

Fig. 15 Average Nusselt Number for the sinusoidal cylinders of the courgation number $\mathrm{G}=\infty, 3,10$ at $\mathrm{Ri}=2$ and $\mathrm{Re}=10,45$, 100,200 with $\lambda=0.1,0.6$.

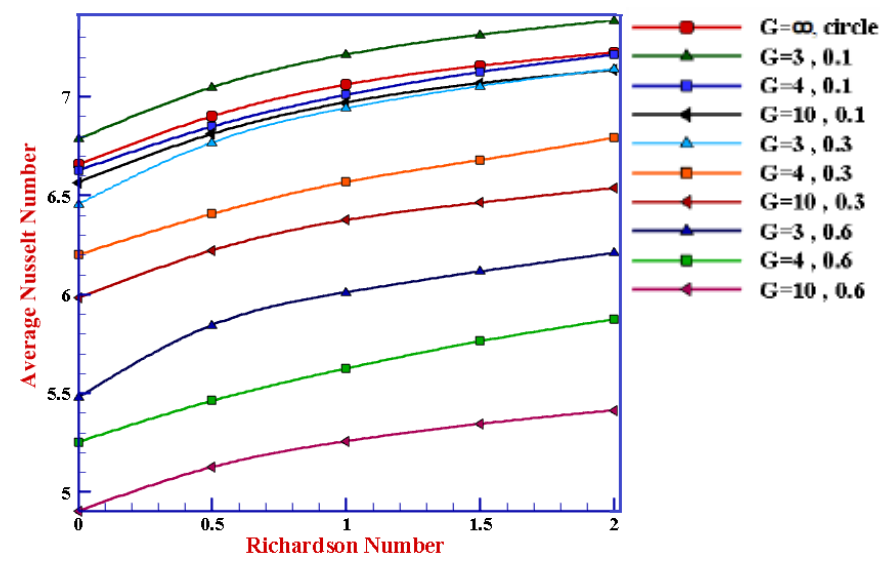

Fig. 17 Average Nusselt Number for sinusoidal cylinders of $G=\infty, 3$, 4 and 10 at $\mathrm{Re}=200$ for $\mathrm{Ri}=0,0.5,1,1.5$ and 2 with $\lambda=0.1$, $0.3,0.6$.

\section{CONCIUSION}

The Galerkin finite element method used to investigate the steady 2-D flow and heat transfer around sinusoidal corrugated cylinder under forced and mixed convection with determine the effect of Reynolds Number, number of undulation and amplitude value on heat transfer rate and flow pattern at $(\mathrm{Re}=10,45,100,200)$ of Corrugation numbers $\mathrm{G}=(\infty, 3,4,5,10)$ with amplitudes $(\lambda=0.1,0.2,0.3,0.6)$ for the $\mathrm{Ri}=$ $(0,1,2)$. It is found that:-

- $\quad$ The corrugation number has an impact on the width of wake cell behind the corrugated cylinder, but the amplitude influences on the strength of the cell.

- The sinusoidal corrugated circular cylinder with corrugation number $(\mathrm{G}=3)$ and amplitude $(\lambda=0.1)$ has highest enhancement rate of heat transfer at $\mathrm{Ri}=2$ and $\mathrm{Re}=200$ in the mixed convection as compared with circular cylinder.

- The sinusoidal corrugated circular cylinder with corrugation number $(\mathrm{G}=10)$ and amplitude $(\lambda=0.6)$ has a lowest dissipation rate of heat transfer in the $\mathrm{Ri}=0$ and $\mathrm{Re}=10$ in the forced convection as compared with circular cylinder. 
- $\quad$ The sinusoidal corrugated circular cylinder with less corrugation number $(\mathrm{G}=3)$ and lower amplitude $(\lambda=0.1)$ has highest surface area that exposed to the incoming flow in addition to the shape of this help to make the one vacuum region of the separation size with high adverse pressure at the rear, also this shape has upper and lower edges inclined to the rear that help to delay the separation flow, which make narrow the wake cells in the vacuum region and close cells to the surface of the sinusoidal cylinder at the rear, and this lead to enhancement of the heat transfer rate.

- The sinusoidal circular cylinder with higher corrugation number $(\mathrm{G}=10)$ and higher amplitude $(\lambda=0.6)$ has many separations that decrease from the effect of the adverse pressure at the rearward, in addition to the thicker boundary layer in the concave saddle surface at the forward decrease the heat transfer rate.

- The heat transfer in the mixed convection is higher than in the forced convection.

- The local Nusselt number has sinusoidal behavior is decreased gradually from the forward to the rearward surface of the sinusoidal corrugated circular cylinder, and the oscillation of this sinusoidal behavior has increased with increase the corrugation number and amplitude value, as compared to the circular cylinder, which has linearly behavior.

- $\quad$ The sinusoidal local Nusselt number oscillates between the higher value at the concave node planes that have a thinner boundary layer and lower value at the convex saddle planes with thicker boundary layer.

- The heat transfer rate is increased with increasing the buoyancy force, which push the flow to the inward of the upper edges and make the wake cells to inter inside caves at the rear, which lead to strongly closer of the cells to the sinusoidal cylinder surface.

- The average Nusselt number is the summation of the sinusoidal local Nusselt numbers, and the higher value is eliminated the lower values of the sinusoidal local Nusselt numbers, therefore, the circular cylinder has higher average Nusselt numbers from another sinusoidal cylinder except that has corrugation number $(\mathrm{G}$ $=3$ and $\lambda=0.1$.

\section{ACKNOWLEDGEMENTS}

It is possible to obtain the highest heat transfer enhancement by Developing the shape of the sinusoidal corrugated circular cylinder to the new Geometry that is contained from two parts of the shape; one divided face is the half of the sinusoidal corrugated circular cylinder at the forward to incoming flow and other shape divisions is the half of the circular cylinder or the sinusoidal corrugated circular cylinder with the less or more corrugation number at the rearward of the cylinder. The chosen of the number of the corrugation number for these divisions is according to the application needs. As well as, it can be used the same sinusoidal corrugated circular cylinders that examined in this paper, but have not equal values of the amplitude $\lambda$.

\section{NOMENCLATURE}

$\begin{array}{ll}C_{p} & \text { specific heat }(\mathrm{J} / \mathrm{kg} \cdot \mathrm{K}) \\ D_{\text {mean }} & \text { mean diameter of the sinusoidal cylinder } \\ g & \text { Gravitational acceleration }\left(\mathrm{m} / \mathrm{s}^{2}\right) \\ G & \text { corrugation number } \\ G r & \text { Grashof number. } \\ k & \text { thermal conductivity }(\mathrm{W} / \mathrm{m} \cdot \mathrm{K}) \\ n & \text { normal direction on the sinusoidal cylinder } \\ N u_{l o c} & \text { loc Local Nusselt number } \\ \overline{N u} & \text { average nusset number } \\ p & \text { dimensional pressure }\left(\mathrm{Pa}=\mathrm{N} / \mathrm{m}^{2}\right) \\ P & \text { non dimensional pressure } \\ P r & \text { prandial number }\end{array}$

$\begin{array}{ll}R e & \text { Reynold number } \\ R i & \text { Richardson number } \\ T & \text { temperature }(\mathrm{K}) \\ T h & \text { temperature hot }(\mathrm{K}) \\ T c & \text { temperature cold }(\mathrm{K}) \\ T^{*} & \text { non - dimensional temperature } \\ u & \text { dimensional velocity components } \\ & \text { lengthwise } \mathrm{x} \text { - axes }(\mathrm{m} / \mathrm{s}) \\ U_{o}-\mathrm{T}_{\mathrm{c}} & \text { maximum velocity of inlet air } \mathrm{m} / \mathrm{s} \\ \mathrm{v} & \text { dimensional velocity components } \\ & \text { lengthwise y- axes (m/s) } \\ V & \text { Non- dimensional velocity components } \\ & \text { lengthwise } \mathrm{Y} \text { - axes } \\ x & \text { horizontal axis }(\mathrm{m}) \\ X & \text { non - dimensional horizontal axis } \\ y & \text { Vertical axis }(\mathrm{m}) \\ Y & \text { non - dimensional vertical axis }\end{array}$

Greek Symbols

$\theta \quad$ theta (angle in radian direction)

$\propto \quad$ thermal diffusivity $\left(\mathrm{m}^{2} / \mathrm{s}\right)$

$\nu \quad$ kinematic viscosity $\left(\mathrm{m}^{2} / \mathrm{s}\right)$

$\mu \quad$ Dynamic viscosity $(\mathrm{kg} / \mathrm{ms})$

$\beta \quad$ volumetric expansion coefficient $(\mathrm{K}-1)$

$\rho \quad$ Density $\left(\mathrm{kg} / \mathrm{m}^{3}\right)$

$\mathcal{L} \quad$ Circumference of sinusoidal circular cylinder $(\mathrm{m})$

$\mathrm{Y} \quad$ penalty parameter

$\phi \quad$ shape or basis functions

$\Omega \quad$ domain

$J \quad$ Jacobian of the residual equations

$\zeta \quad$ Unit square coordinate in horizontal Direction

$\ell \quad$ Unit square coordinate in vertical Direction

$\psi \quad$ non dimensional stream function

$\forall \quad$ angle with Unit square

$\lambda \quad$ amplitude value

$\infty \quad$ circuler cylinder

\section{Superscripts}

st $\quad$ Stream function

$s \quad$ total Nodes number

$z \quad$ iterative indicator

\begin{tabular}{ll}
\multicolumn{2}{l}{ Subscripts } \\
mean & $\begin{array}{l}\text { Base diameter or radius of } \\
\text { cylinder }\end{array}$ \\
& Maximum of the velocity \\
$o$ & cold \\
$c$ & hot \\
$h$ & Local \\
$l o c$ & Node number \\
$b$ &
\end{tabular}

\section{REFERENCES}

Amit, D., Rishabh, G., and László, B., 2018 " Cross buoyancy mixed convection from a heated cylinder placed asymmetrically in a channel", International Communications in Heat and Mass Transfer, 95, 139146. https://doi.org/10.1016/j.icheatmasstransfer.2018.05.007

Amit, D., and Mudassir, H., 2012, " Flow and heat transfer over a trapezoidal cylinder: steady and unsteady regimes", Asia-Pacific Journal of Chemical Engineering, 247- 667. http://dx.doi.org/10.1002/apj.1678 
Ammar, A., Hameed K., Farooq H., Azher M., and Isam M. A., 2019, "Natural convection among inner corrugated cylinders inside wavy enclosure filled with nanofluid superposed in porous- nanofluid layers" International Communications in Heat and Mass Transfer, 109, (104350).

https://doi.org/10.1016/j.icheatmasstransfer.2019.104350

Amnart, B., and Withada, J., 2018, "Effect Of Location Transverse Plane For 45- Degree V- Baffle On Flow and Heat Transfer Mechanims In Asquare Channel ", Frontiers in Heat and Mass Transfe, 2151-8629, 11- 29.

http://dx.doi.org/10.5098/hmt.11.29

Atul, S., and Eswaran, V., 2010,"heat and fluid flow across a square cylinder in the tow dimensional laminar flow regime", Numerical Heat Transfer: Int. J of Computation and Methodology, 45 (3), 247 - 269. http://dx.doi.org/10.1080/10407780490278562

Batchelor, M., 1993, "An Introduction to Fluid Dynamics convection", Cambridge University Press.

http://doi.org/10.1017/CBO9780511800955

Dennis, S. G., Hugh, H., and Neville, S., 1968, "Steady laminar forced convection from a circular cylinder at low Reynolds number", Phys . Fluids, 11, 933- 940.

http://doi.org/10.1063/1.1692061

Dipankar, C., and Bittagopal, M., 2015 "Effect of Thermal Buoyancy on Fluid Flow and Heat Transfer Across a Semicircular Cylinder in Cross-Flow at Low Reynolds Numbers, " Numerical Heat Transfer, International Journal of Computation and Methodology, 67, 436-453. http://dx.doi.org/10.1080/10407782.2014.937248

Gautam, B., and Sandip, S., 2009, "Effect of Thermal Buoyancy on Vortex Shedding Past a Circular Cylinder in Cross- Flow at Low Reynolds Numbers, " International Journal of Heat and Mass Transfer, 52,1897-1912.

https://doi.org/10.1016/j.ijheatmasstransfer.2008.08.034

Hassan, M. B., 1984, "Laminar combined convection from a horizontal cylinder parallel and contra flow", International Journal Heat Mass Transfer, 27, 15-27,

http://doi.org/10.1016/0017-9310(84)90233-3

Hussein, M., J., Farooq, H., A., Qusay, R., A., Hameed, K., H., and Salwan, O., 2019, "Enttropy Generation Analysis of a Natural Convection Inside a Sinusoidal Encloser With Different Shapes of Cylinders", Frontiers in Heat and Mass Transfer, 2151- 8629, 1- 9. https://doi.org/10.5098/hmt.12.227

Isam M., A., Ammar, A., Ruqaia A., Hammed K., and Farooq H., 2020, "Natural Convection Heat Transfer for Adiabatic Circular Cylinder Inside Trapezoidal Enclosure Filled with Nanofluid Superposed Porous- Nanofluid Layer ", FME Transactions, 48, 82- 89. https://doi.org/10.5937/fmet2001082M

James, R., Mathieu, S., and Wei, H., 2020 "Non-Uniform Suction Control of Flow around a Circular Cylinder ", International Journal of Heat and Fluid Flow, 82 (108559), 1- 21.

https://doi.org/10.1016/j.ijheatfluidflow.2020.108559

Lam, K.. and Lin, Y. F., 2009, "Effects of Wavelength and Amplitude of a Wavy Cylinder in Cross-Flow at Low Reynolds Numbers", Journal Fluid Mech, 620, 195-220 http://dx.doi.org/10.1017/S0022112008004217

Prakash, B., and Chha, E., 2007, "A numerical study of the steady forced convection heat transfer from an unconfined circular cylinder", Heat Mass Tsfer, 43, 639-648. http:// doi.org/10.1007/s00231-006-0155-1

Rajani, B. N., Kandasamy A., and Sekhar, M., 2009, "Numerical Simulation of Laminar Flow Past a Circular Cylinder", Applied Mathematical Modelling, 33, 1228-1247.

http://doi.org/10.1016/j.apm.2008.01.017

Rehena, N., 2011, "Mixed Magentoconvection in a lid-driven cavity with a sinusoidal wavy wall and a central heat conducting body", Journal of Naval Architecture and Marine Engineering, 7, 13- 14. https://doi.org/ 10.3329/jname.v8i1.6793

Rupad, M. D., and Spencer, J., S., 2001, "Flow Past a Square-Section Cylinder with a Wavy Stagnation Face", Journal Fluid Mech, 426, 263-295.

https://doi.org/10.1017/S0022112000002299

Subhankar, S., Sanjay, M., and Gautam B., 2011 "Flow Past a Square Cylinder at Low Reynolds Numbers", International Journal For Numerical Methods In Fluids, 67, 1160-1174 http://dx.doi.org/ 10.1002/fld.2416

Tanmay, B., Satyajit, R., Trishna, P., and Ioan, A., P., 2006, "Natural convection in a square cavity filled with a porous medium Effects of various thermal boundary conditions", International Journal of Heat and Mass Transfer, 49, 1430-1441.

https://doi.org/10.1016/j.ijheatmasstransfer.2005.09.018 